\title{
The Effect of Different Injection Strategies and Intake Conditions on the Emissions Characteristics in a Diesel Engine
}

\author{
M. Gorji-Bandpy, S. Soleimani, and D. D. Ganji \\ Department of Mechanical Engineering, University of Mazandaran, P. O. Box 484, Babol, Iran \\ Correspondence should be addressed to S. Soleimani, zzsajad@yahoo.com
}

Received 21 October 2008; Revised 16 January 2009; Accepted 11 March 2009

Recommended by Chonggang Wang

\begin{abstract}
Choosing various injection strategies and intake conditions are potentially effective techniques to reduce exhaust emission from diesel engines. The purpose of this study is to investigate the effect of different spray incoming angles, different spray cone angles, different injection timing, and different intake temperatures together with emission characteristics on a heavy duty diesel engine via three dimensional computational fluid dynamics (CFD) procedures. Furthermore the effect of multiple injector combustion chamber and its benefits in pollutant reduction is studied. The principal results show the significant differences in soot and NO generation during combustion between above different strategies.
\end{abstract}

Copyright (C) 2009 M. Gorji-Bandpy et al. This is an open access article distributed under the Creative Commons Attribution License, which permits unrestricted use, distribution, and reproduction in any medium, provided the original work is properly cited.

\section{Introduction}

Automobiles and trucks afford such a convenient means of transportation that they will continue to be demanded by our mobile society. As a result, the requirements to meet the challenge of producing cleaner and more efficient power-plants will intensify further in the next years. This challenge requires an increased commitment to research by the transportation industry. The industry has already improved engine performance significantly through the use of new technologies such as ultrahigh injection pressure fuel sprays (e.g., to reduce pollutant emission levels) and the use of advanced materials (e.g., ceramics to influence engine heat transfer losses). More recently, advanced computer models are finding increased use in the industry as a tool to accelerate the pace of change. The internal combustion engine represents one of the more challenging fluid mechanics problems to model because the flow is compressible, low Mach number, turbulent, unsteady, cyclic, and nonstationary, both spatially and temporally. The combustion characteristics are greatly influenced by the details of the fuel preparation process, and the distribution of fuel in the engine which is, in turn, controlled by the in-cylinder fluid mechanics. Fuel injection introduces the complexity of describing the physics of dense, vaporizing two-phase flows.
Pollutant emissions are controlled by the details of the turbulent fuel-air mixing and combustion processes, and a detailed understanding of these processes is required in order to improve performance and reduce emissions while not compromising fuel economy. The need for maximum fuel economy and minimum pollution and noise in diesel engines requires a detailed investigation of experimental, numerical, and theoretical on the characteristics of the fuel injection systems [1-4], but much must be done to develop very accurate mathematical models to reduce the long and expensive experimental testing $[5,6]$.

In spite of the detailed nature of even the most comprehensive of engine codes, they will not be entirely predictive for the foreseeable future due to the wide range of length and time scales needed to describe engine fluid mechanics. Thus, it is necessary to introduce submodels for processes that occur on time and length scales that are too short to be resolved such as atomization, drop drag and vaporization, drop breakup and coalescence, drop turbulence dispersion and turbulence modulation effects, spray-wall interaction, and turbulent combustion. The use of submodels to describe unresolved physical processes necessarily introduces empiricism into computations. However, the compromise between accuracy and feasibility of computation is justified by the insight which model calculations offer. Confidence in the 
TABLE 1: Engine specifications [20].

\begin{tabular}{|c|c|c|c|}
\hline Bore & $137.19 \mathrm{~mm}$ & $\begin{array}{l}\text { Intake } \\
\text { pressure }\end{array}$ & $1.85 \mathrm{bar}$ \\
\hline Stroke & $165.1 \mathrm{~mm}$ & $\begin{array}{l}\text { Intake valve } \\
\text { close timing }\end{array}$ & 147 deg BTDC \\
\hline $\begin{array}{l}\text { Connecting } \\
\text { rod length }\end{array}$ & $261.62 \mathrm{~mm}$ & $\begin{array}{l}\text { Injection } \\
\text { timing }\end{array}$ & $-8.5 \sim 10.1$ ATDC \\
\hline $\begin{array}{l}\text { Compression } \\
\text { ratio }\end{array}$ & 15 & Fuel rate & $200 \mathrm{~mm}^{3} / \mathrm{cyl}$ \\
\hline Piston crown & Mexican hat & Engine speed & $1600 \mathrm{rev} / \mathrm{min}$ \\
\hline
\end{tabular}

model predictions and knowledge of their limitations is gained by comparison with experiments [7-10].

In general, there are some modifications in injection design and intake conditions to reduce emissions. The aim of this study is to investigate these modifications. Thus parameters like number of nozzle, fuel incoming angle, spray cone angle, injection timing, and intake temperature are investigated on a specified (Direct Injection) DI diesel engine.

The simulation here performed via AVL-fire (a strong commercial code). In further sections, the details of applied models and submodels together with validation status, simulation trustworthy condition, and results of different injection strategies and intake conditions are offered.

\section{Analysis Model}

Spray simulations involve multiphase flow phenomena and as such require the numerical solution of conservation equations for the gas and the liquid phase simultaneously. With respect to the liquid phase, spray calculations is based on a statistical method referred to as the discrete droplet method (DDM) [11]. This operates by solving ordinary differential equations for the trajectory, momentum and heat, and mass transfer of single droplets, each being a member of a group of identical noninteracting droplets termed a parcel. Thus one member of the group represents the behavior of the complete parcel. Droplet parcels are introduced in the flow domain with initial conditions of position, size, velocity, temperature, and number of particles in the parcel. Introduction of droplets is emerging from a nozzle as a spray and entering the flow domain through the inlet areas as a gas-liquid mixture. The atomization process of sprays is accounted for with distinctive submodels. The droplet-gas momentum exchange, turbulent dispersion, evaporation of droplets, secondary break-up, droplet collision, and dropletwall interaction are covered with a comprehensive set of models. The vapor of evaporating droplets is used as a source term of an additional transport equation for the vapor void fraction in Eulerian formulation.

The droplets are tracked in a Lagrangian way through the computational grid used for solving the gas phase partial differential equations. Full two-way coupling interaction between the gas and liquid phases is taken into account. In situations of negligible influence of the dispersed phase on the continuous one, the gas phase flow can be simulated

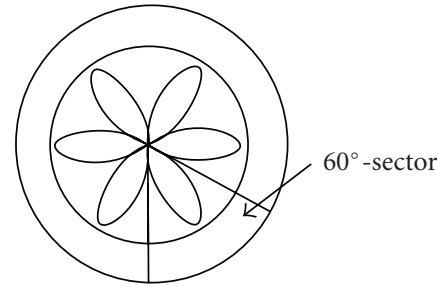

FIGURE 1: Schematically view of combustion chamber and its $60^{\circ}$ sector (view from top).



Figure 2: $60^{\circ}$-sector computational grid at Top Dead Center (TDC).

in advance, and the droplet simulation can be performed afterwards.

2.1. Submodels. For this work, computational fluid dynamics simulation is used as the modeling platform which our enhancements to critical submodels including spray, combustion, and emission submodels are as follows.

(i) Spray models: wall interaction model is walljet [12], evaporation model is Dukowicz [13], and breakup model is wave standard [14].

(ii) Emission models: NO model is Zel'dovich $[15,16]$, and soot model is Kennedy-Hiroyasu-Magnussen [17].

(iii) Turbulence model on the spray particles: Gosman and Loannides [18].

(iv) Turbulant model: $k-\varepsilon$ standard [19].

2.2. Simulation Engine. The engine simulation was conducted using a single cylinder version of a truck engine (Caterpillar 3406 truck). Details of the engine specification are summarized in Table 1.

While ATDC and BTDC are After Top Dead Center and Before Top Dead Center, respectively. To increase computational efficiency, a $60^{\circ}$-sector computational mesh was used (Figure 1). Periodic boundary conditions were assumed in the axial direction of $60^{\circ}$-sector computational mesh. Figure 2 shows the $60^{\circ}$-sector computational grid at (Top Dead Center) TDC.

\subsection{Calculation Procedure}

2.3.1. Model Validity. In Figures 3 and 4 a comparison between present simulation and measured [20] for incylinder pressure and rate of heat release was first conducted. This was done to ensure that the prediction made with this 


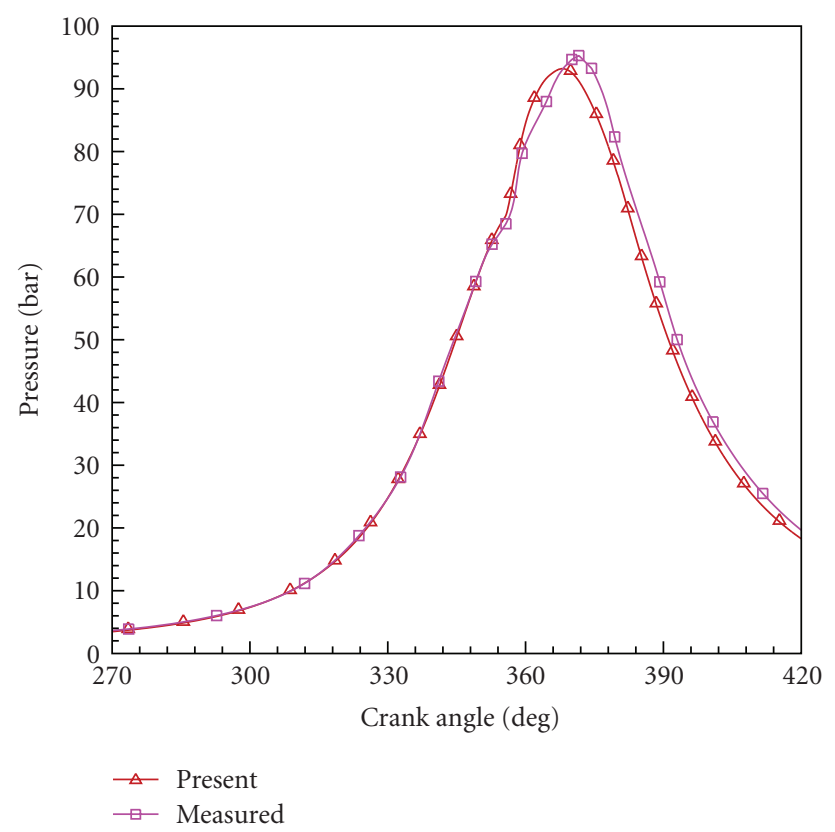

Figure 3: Variations of intake pressure against crank angle for measured and present work.

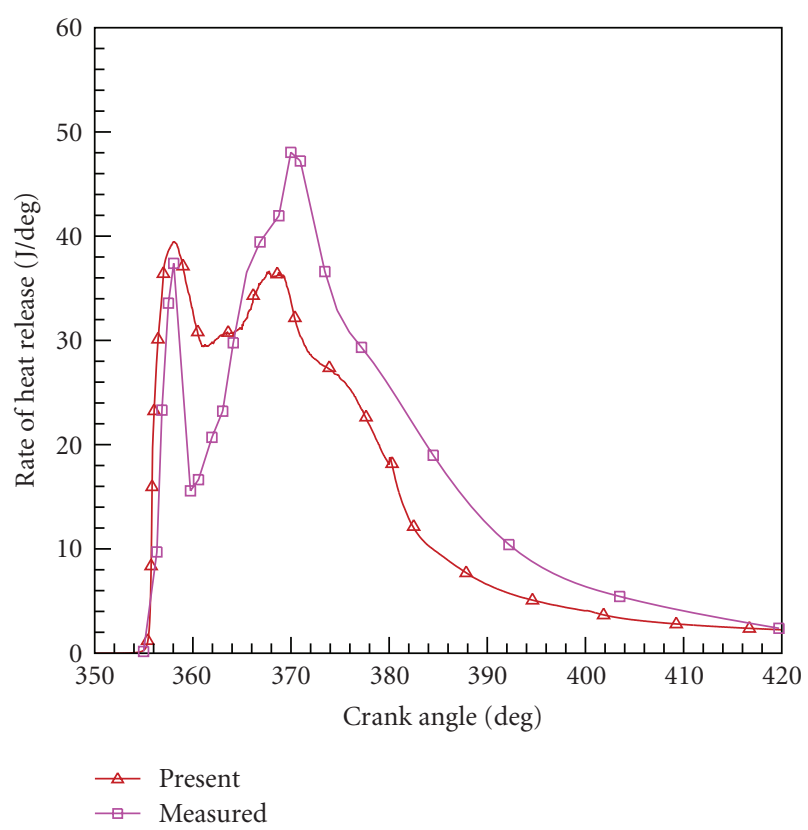

Figure 4: Variations of rate of heat release against crank angle for measured and present work.

work is trustworthy. The pressure diagram is divided into two parts: the first one is before start of injection, and the second is after the start of injection. In former part the present work well coincides with the measured results, however in latter part a very trivial difference is observed.

The diagram of rate of heat release has two major zones, premixed combustion and diffusive combustion. In premixed zone a high amount of fuel is ignited immediately, while in diffusive zone fuel ignites smoothly with diffusive



FIGURE 5: Variations of in-cylinder temperature against crank angle for three meshes of present, fined, and coarse.

flame. In this work the premixed zone is well predicted but in diffusive zone there is a difference between the present work and measured data maximally $4.8 \%$ at crank angle of 370 degree, however the trends of measured and present work are relatively similar.

The results indicate that the comparisons between present simulation and measured [20] are relatively in good agreement, thus present simulation is reliable to predict the engine performance near real conditions. In this section for validating the present work with experimental results [20], tetradecane is used as the injected fuel.

2.3.2. Grid Independency. As mentioned above, spray calculations are based on a statistical method referred to the discrete droplet method (DDM) [11]. It is known that the spray model has its limitation to work with fine meshes, and the actual problem is in the lacking statistical convergence per computational cell [21]. According to Dahlen [22] for injector nozzle with diameter of $0.2 \mathrm{~mm}$, equivalent average cell size at (Start Of Injection) SOI, $0.6 \mathrm{~mm}$ is suggested (3 times). In this work for the injector nozzle with diameter of $0.259 \mathrm{~mm}$, equivalent average cell size at SOI, the value of $0.797 \mathrm{~mm}$ is exerted.

This size is exerted for grids present and fined, however grid fined is more fined at axial direction. Another grid with coarse mesh (coarse) is exerted for the comparison.

Grid present has 60400, and grid fined has 84800 meshes at Bottom Dead Center (both have the same mesh at TDC). Grid coarse has 39400 meshes at bottom dead center (hereafter the injected fuel is $\mathrm{C}_{13} \mathrm{H}_{28}$ ).

Figures 5 and 6 indicate that the grid present is a good choice for our goal because it is more economic than grid fined, while grid coarse is too coarse for good predictions. 


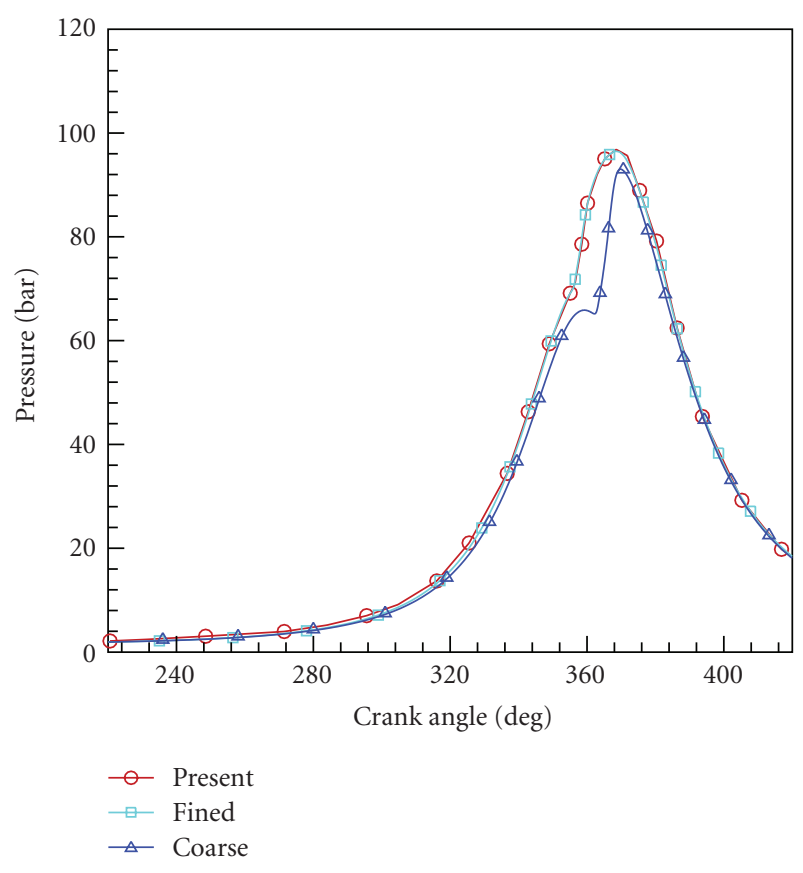

FIGURE 6: Variations of in-cylinder pressure against crank angle for three meshes of present, fined, and coarse.



FIGURE 7: Schematically view of incoming spray in a combustion chamber (view from front).

\section{Results and Discussion}

There are many parameters in specifying a diesel engine behavior. These parameters have effect on heat transfer, fuelair mixture, combustion, and so forth.

In this work different conditions for fuel injection are considered, the fuel incoming angle, and the fuel cone angle are investigated. Furthermore the effect of multiple injectors is investigated. Different injection timing and different initial conditions of combustion chamber are taken under consideration. It should be notified that when the above parameters were under investigation, all the parameters except one parameter considered intact. First of all we focus on the effect of different fuel incoming angles in the combustion chamber.

3.1. Incoming Angle. In this section different injection angles are investigated for the engine's performance and optimization. Corresponding to Figure 7 the incoming angle is illustrated by the angle between injection direction and

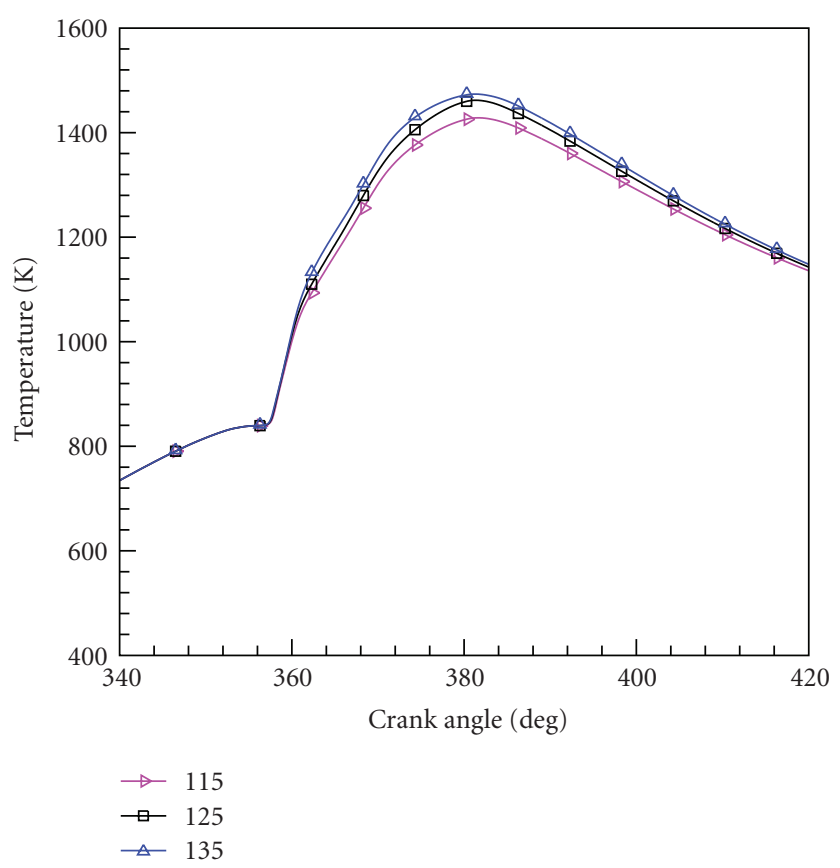

FIGURE 8: Variations of in-cylinder temperature against crank angle for three cases of $\alpha=115,125$, and 135 .

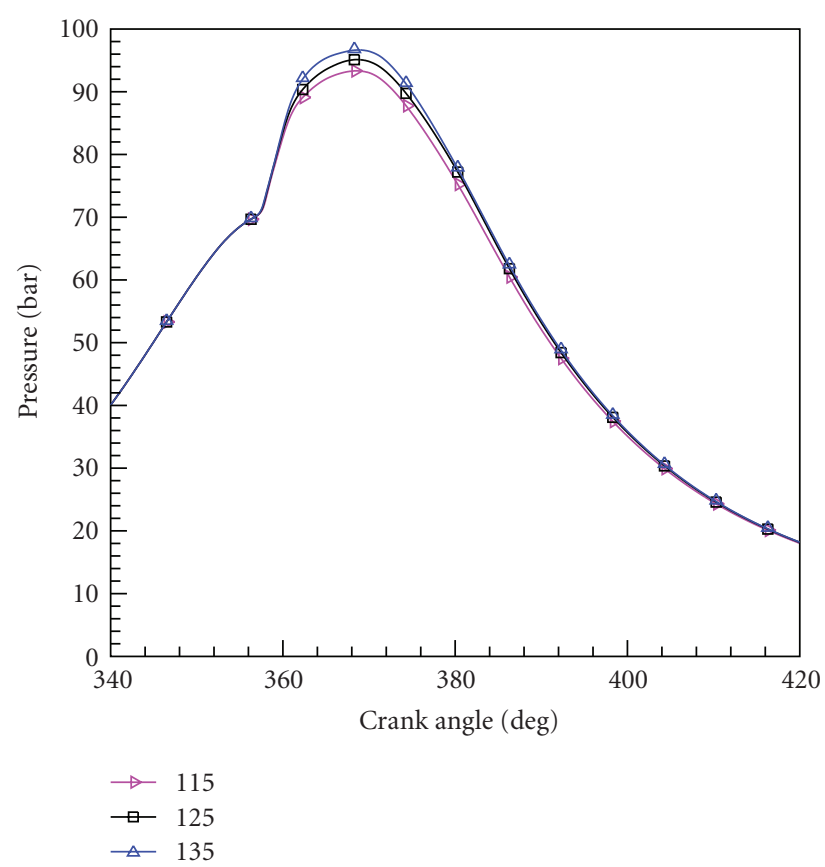

FIGURE 9: Variations of in-cylinder pressure against crank angle for three cases of $\alpha=115,125$, and 135.

axial direction by $\alpha / 2$. For this work the different angles of $\alpha=115,125$, and 135 degrees were considered.

Figures 8 and 9 indicate the variations of in-cylinder temperature and pressure, respectively. By increasing the injection angle, in-cylinder temperature and pressure increase slightly. This is because of better mixture of fuel-air and so better combustion. 


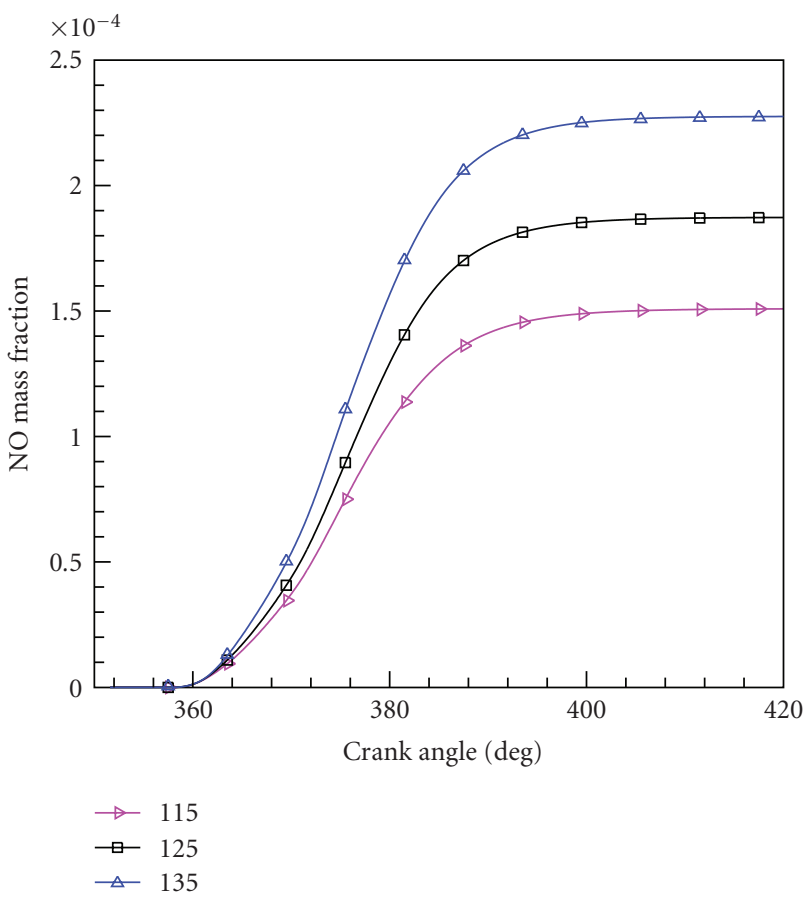

Figure 10: Variations of NO mass fraction against crank angle for three cases of $\alpha=115,125$, and 135 .

Taking a glance on Figures 10 and 11, it is obvious that, by increasing injection angle NO production increases whereas soot production decreases; this is because by increasing injection angle the injected fuel recedes from wall and conducts to the piston crown, so fuel exposures to hotter air which leads to more NO production. Furthermore the increase of in-cylinder temperature is another reason for increasing NO production.

Generally soot pollutant increases due to weakening of diffusive flame. When the angle of injected fuel increases, fuel spreads much better and monotonous and the combustion efficiency in the zone of diffusive flame increases, therefore the soot pollutant decreases. This is because the more the injected fuel angle increases, the more it exposes to the oxygen and therefore the more produced soot burns.

By increasing injection angle the in-cylinder pressure and temperature increase but it is not very significant.

3.2. Injection Cone Angle. The fuel injection cone angle when spraying to the cylinder is shown in Figure 12.

Injection cone angle is the function of in-cylinder air density $\rho_{g}$, injected fuel density $\rho_{I}$, and geometry constant $A$, as follow [23]:

$$
\tan \frac{\theta}{2}=\frac{1}{A} 4 \pi\left(\frac{\rho_{g}}{\rho_{l}}\right)^{1 / 2} \frac{\sqrt{3}}{6},
$$

where $A$ is the function of length $\left(L_{n}\right)$ and diameter $\left(d_{n}\right)$ of injector hole (Figure 13).

$A$ is identified as follow:

$$
A=3+0.28\left(\frac{L_{n}}{d_{n}}\right)
$$

Thus By changing the nozzle geometry $\left(L_{n}\right.$ and $\left.d_{n}\right)$, different cone angles will be observed.

Regarding to experimental investigation performed by Payri et al. [24] nozzle geometry can effect on spray behavior (vaporization, mixing, and liquid length). In this section the effect of nozzle geometry on mentioned engine's behavior of producing pollutant is studied. Thus three cone angles of $\theta=10,14$, and 18 degree which were produced because of different nozzle geometry are compared with each other.

By increasing the injection cone angle there will be a better fuel-air mixture, this condition together with higher and easier access to oxygen leads to higher NO production.

As shown in Figure 15 by increasing injection cone angle at primary crank angles higher amounts of soot are produced while in latter crank angles higher oxidation occurs. These two controvert phenomena lead to similar soot production for all three cases at exhaust valve crank angle. Indeed, after the start of fuel combustion, the soot pollutant produces because of the thermal pyrolysis and in latter crank angles soot burns because of oxidation. The increase of cone angle, leads to increasing the thermal pyrolysis and therefore soot production, on the other hand in latter stages increasing cone angle, leads to burning soot in higher rate because of easier and higher access to oxygen.

Thus, in this engine increasing cone angle from 10 to 18 degrees leads to $8 \%$ increasing in NO mass fraction while the amount of exhausted soot mass fraction was similar for all three cases, however the procedure of producing and oxidation is different.

3.3. Retard of Injection Timing. One of the most effective parameter in an engine's performance and exhausted emission is the adjust of injection timing. Here different injection timings are applied as follow.

Start of injection at 350.5, 349.5, and 346.5 degrees which are represented by adv0, adv3, and adv6, respectively. The duration of injection is the same for all three cases.

As shown in above Figures, different injection timing causes significant changes in in-cylinder conditions and exhaust emissions. When the injection timing is advanced fuel has higher possibility to mix with air and this can lead to higher temperature and pressure.

More in-cylinder temperature leads to more NO production on the basis of Zel'dovich mechanism. The relation between NO production and in-cylinder temperature is as follow [15]:

$$
\frac{d[\mathrm{NO}]}{d[t]}=\frac{6 \times 10^{16}}{T^{1 / 2}} \exp \left(\frac{-69090}{T}\right)\left[O_{2}\right]^{1 / 2}\left[N_{2}\right] .
$$

By observing Figures 19(a) and 19(b) it is understood that when injection timing is advanced from the crank angle of 351.5 to 349.5 and 346.5 degrees the soot production decreased. As shown in Figure 19(a), i?tex cmt="We changed " $D_{n}$ " to " $d_{n}$ " in Figure 13. Please check."?; although by advancing the injection timing, the soot production increases in primary crank angles, it decreases in higher rate in latter crank angles due to higher oxidation due to higher incylinder temperature. Another reason is that retarding the 


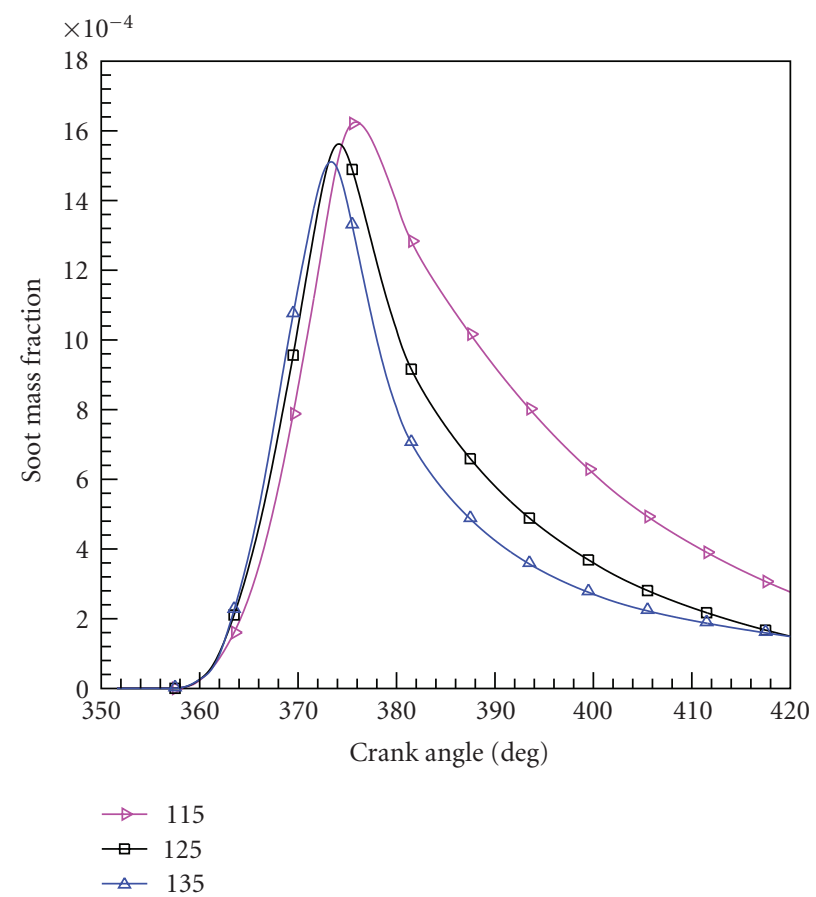

(a)

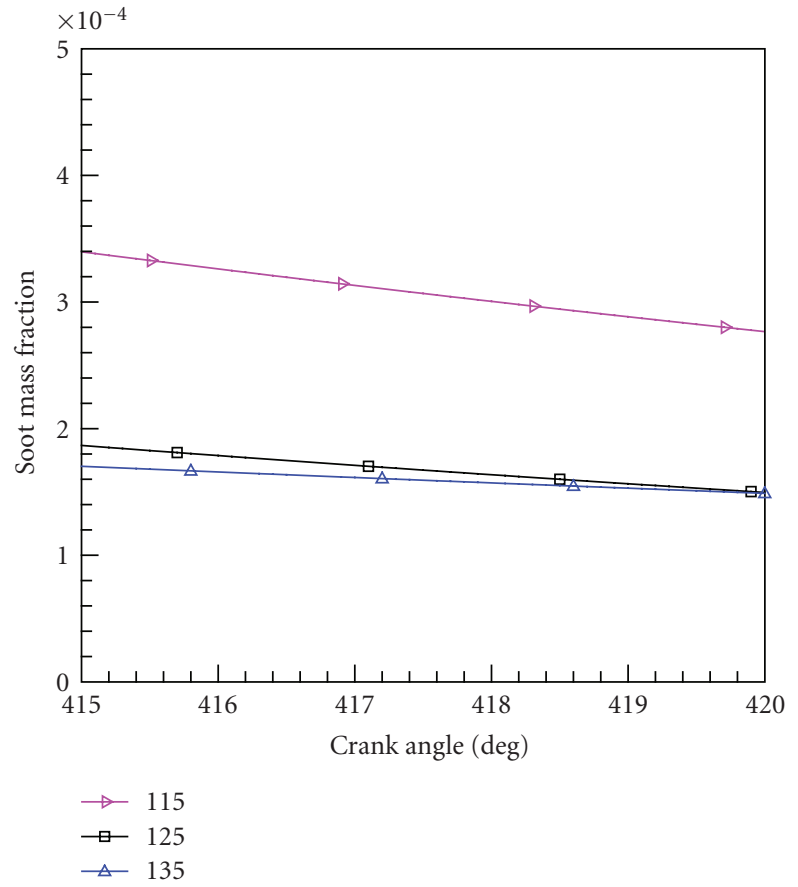

(b)

FIGURE 11: (a) Variations of soot mass fraction against crank angle for three cases of $\alpha=115,125$, and 135. (b) Variations of soot mass fraction against crank angle for three cases of $\alpha=115,125$, and 135.

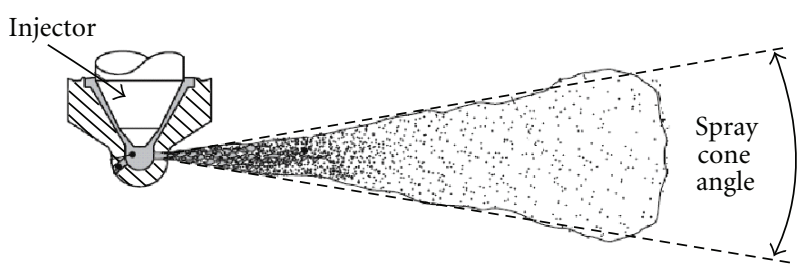

FIGURE 12: Schematically view of injection cone angle.

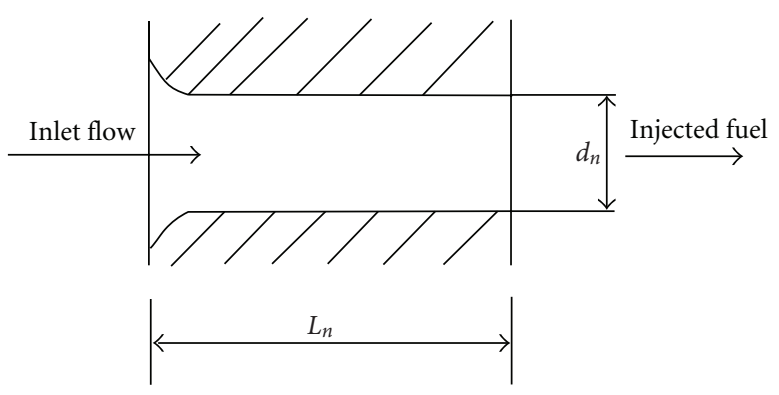

FIGURE 13: Schematically view of a spray nozzle.

injection timing causes soot stay out of piston crown and therefore causes less oxidation because of exposing to out of piston crown colder air. Furthermore by retarding the injection timing, the sufficient time for oxidation in latter crank angles decreases. This is due to lower amount of time between the start of injection and exhaust valve opening crank angle.

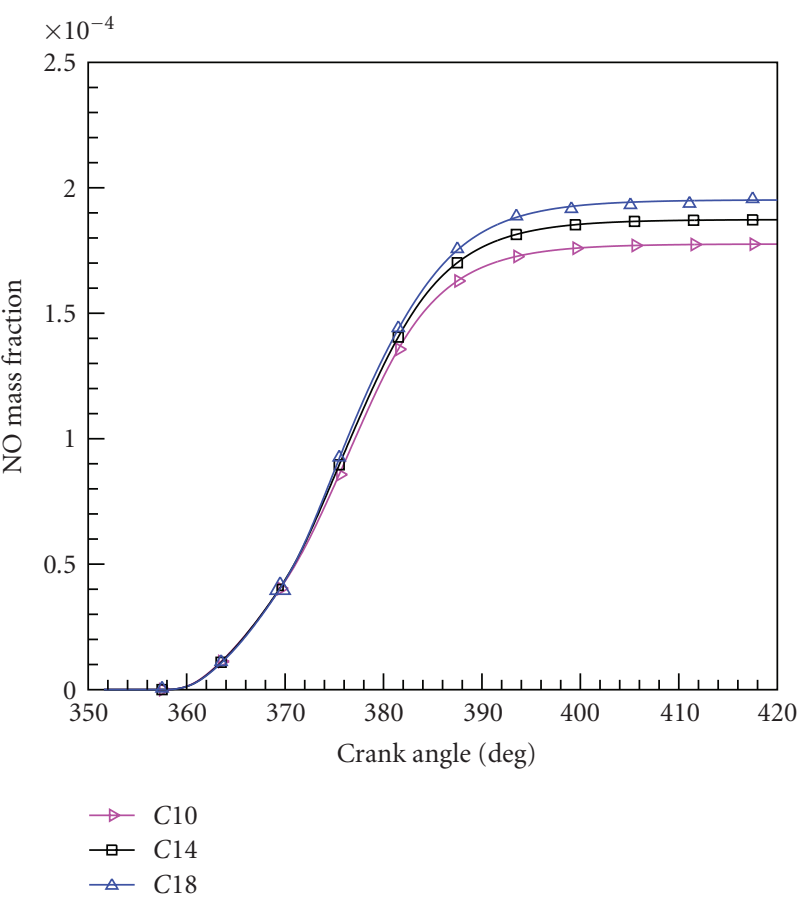

FIGURE 14: Variations of NO mass fraction against crank angle for different cone angles.

3.4. Intake Temperature. By increasing intake temperature, the in-cylinder temperature increases which leads to increasing NO production according to Zel'dovich mechanism.

As shown in Figures 22(a) and 22(b), the increase of intake temperature has effect on soot production. This 


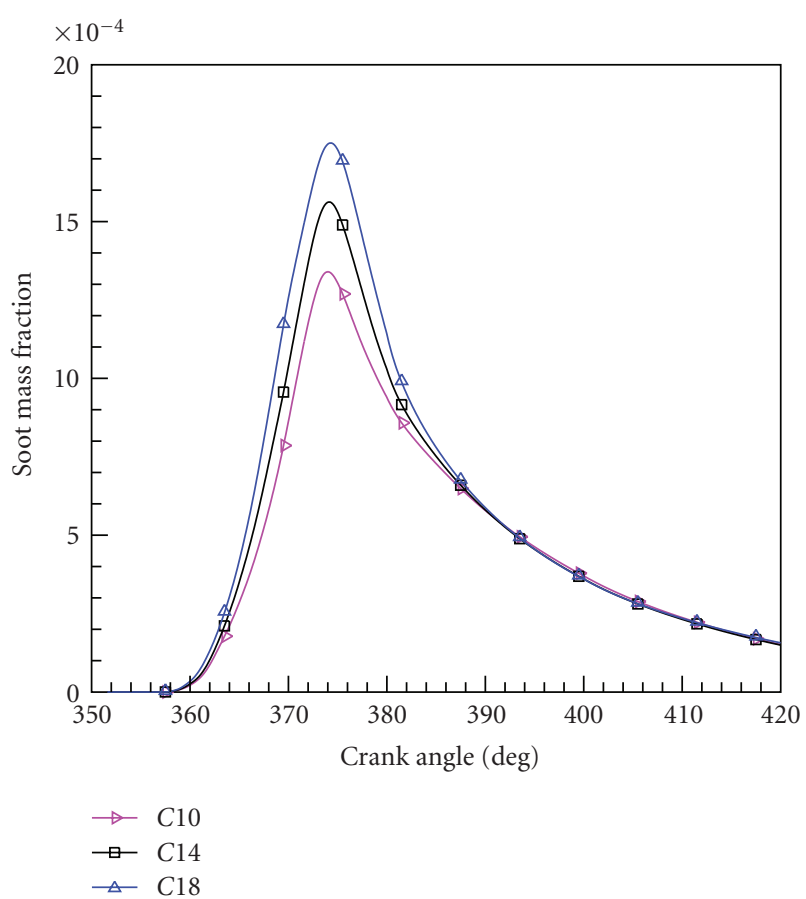

FIGURE 15: Variations of soot mass fraction against crank angle for different cone angles.



FIGURE 16: Variations of in-cylinder temperature against crank angle.

is due to increase of in-cylinder temperature. At primary crank angles soot increases, and in latter crank angles soot decreases due to more oxidation. These two adverse phenomena lead to soot reduction finally.

3.5. Multiinjectors. Now we turn our consideration to the combustion chamber with more than one injector (multiple injector combustion system).

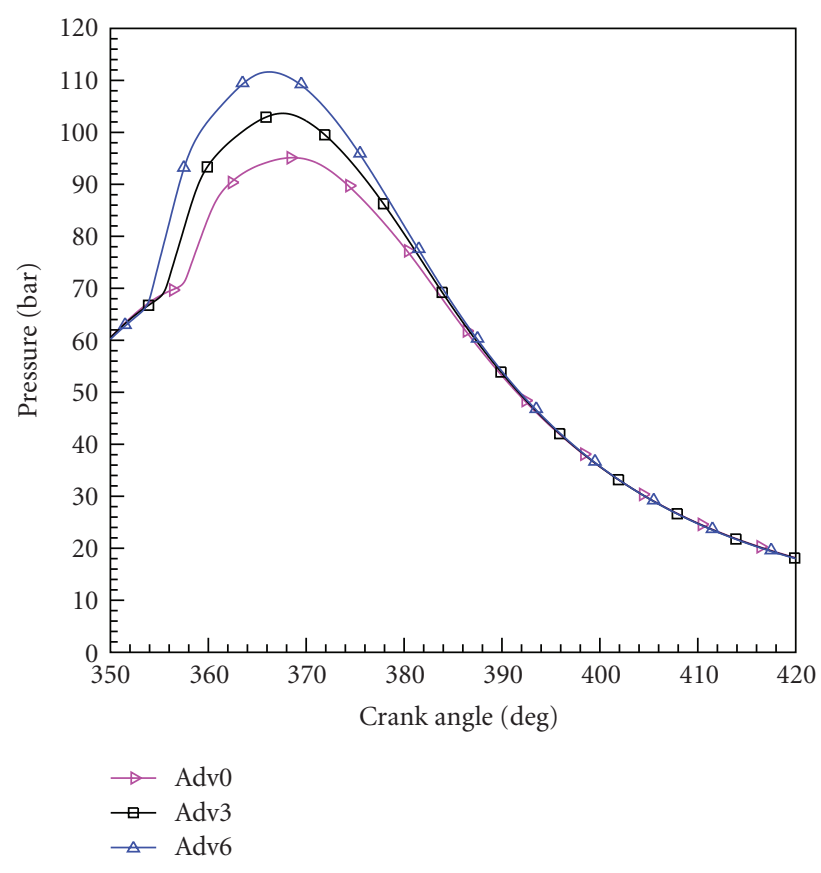

FIGURE 17: Variations of in-cylinder pressure against crank angle.

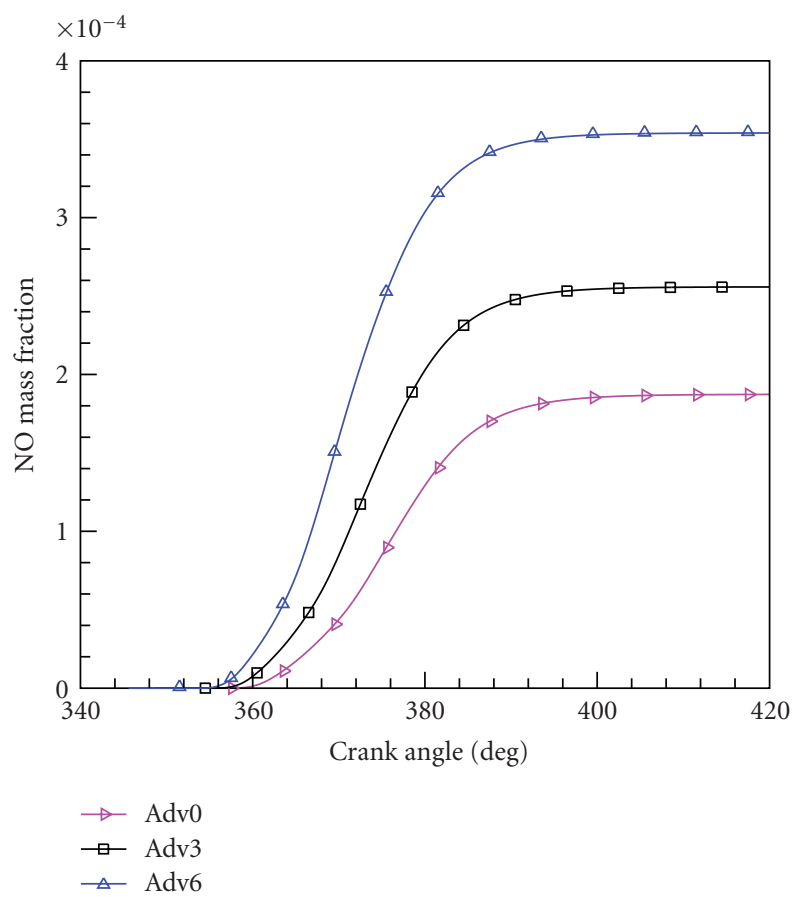

FIGURE 18: Variations of NO mass fraction against crank angle.

Figure 23 shows two combustion chambers (view from top). The left one is a schematic view of a combustion chamber with single injector and 6 holes, while the right one is a schematic view of a combustion chamber with 6 injectors each has one hole.

As mentioned before, for simplicity and economic efficiency, only $60^{\circ}$-sector of combustion chamber is simulated (Figures 23 and 24). 


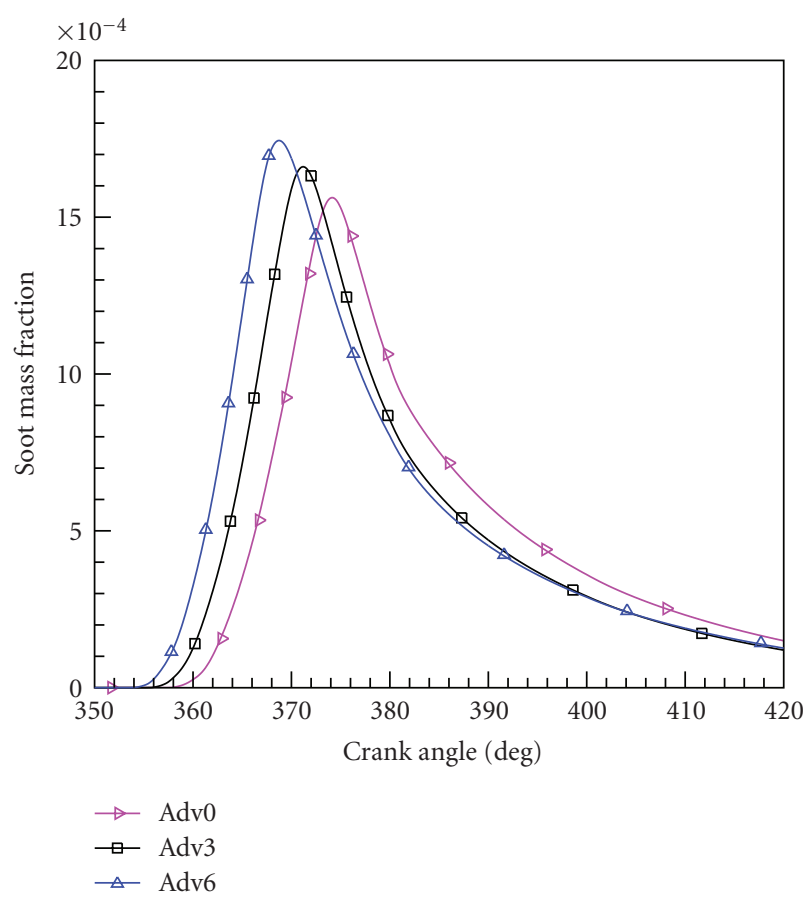

(a)

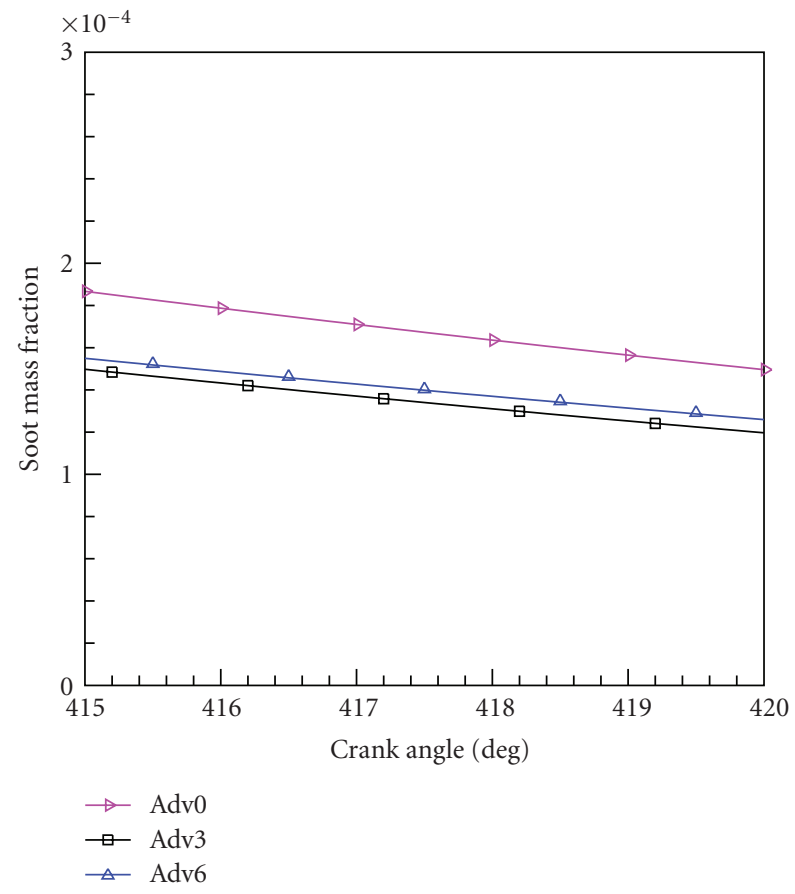

(b)

FIGURE 19: (a) Variations of soot mass fraction against crank angle. (b) Variations of soot mass fraction against crank angle.

Generally the cylinder's wall is much cooler than incylinder environment. In the case of 6 injectors the injection is much nearer to the wall than the case of 1 injector. This vicinity of injection to the wall leads to decreasing the in-cylinder temperature significantly. A deeper regard on Figure 25 denotes that there is a sudden reduction in

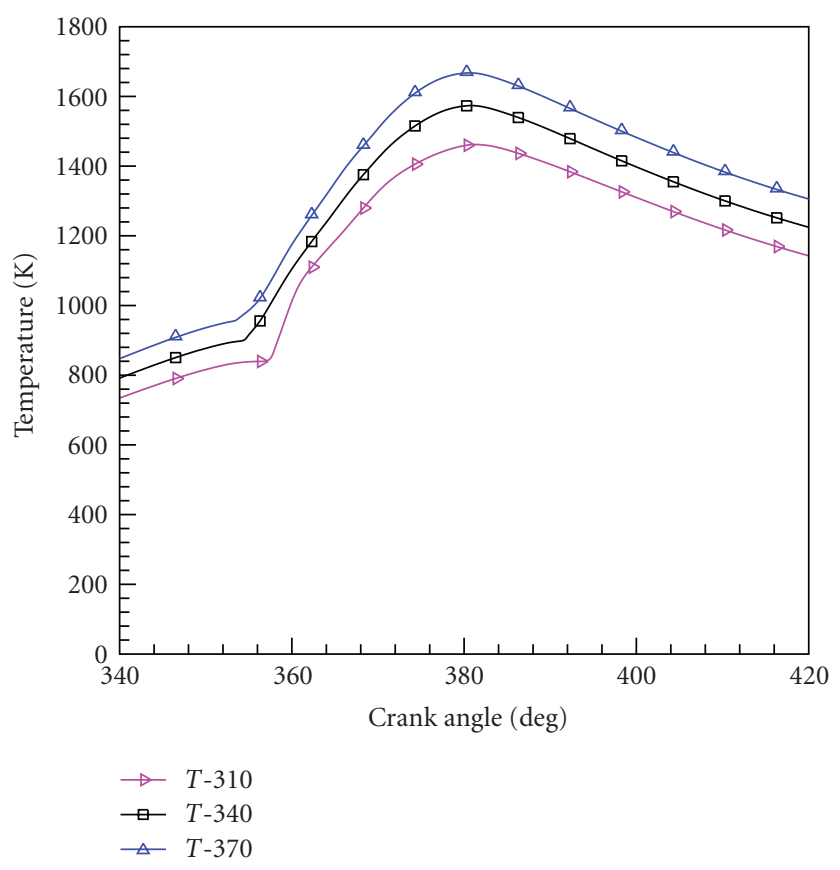

FIGURE 20: Variations of in-cylinder temperature against crank angle.

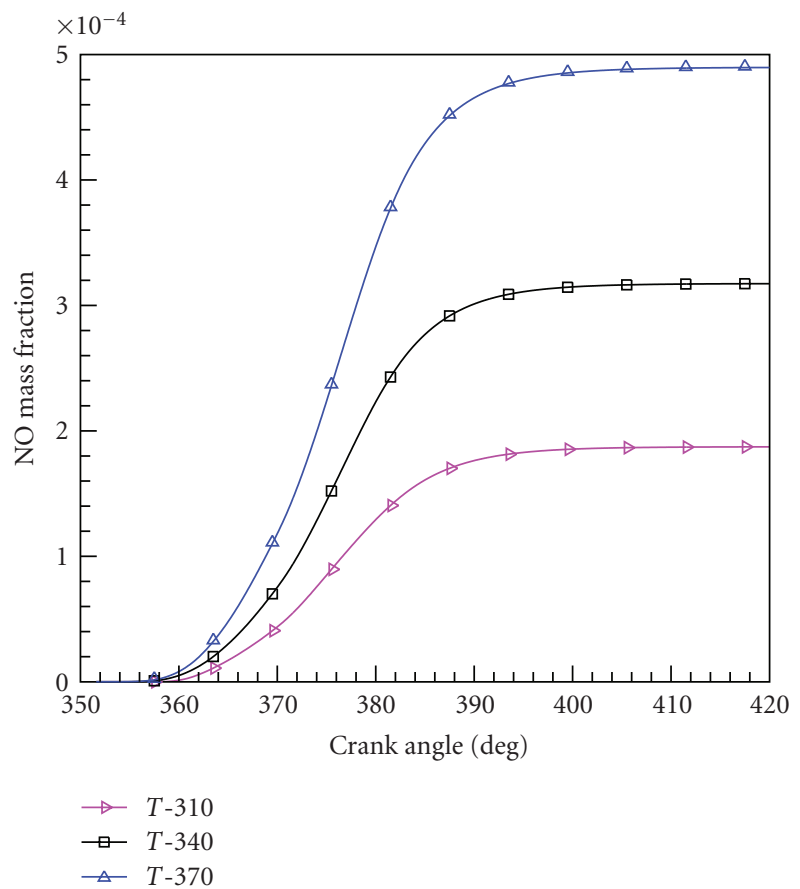

FigURE 21: Variations of NO mass fraction against crank angle.

temperature for the case of 6 injectors just a little after TDC. This phenomenon happens because of high vicinity of injection to the wall in crank angles after TDC. Indeed, due to impact of fuel flame to the cold wall, some amount of fuel does not ignite in primary crank angles. This leads to another sudden ignition in latter crank angle $\left(365^{\circ}\right)$. 


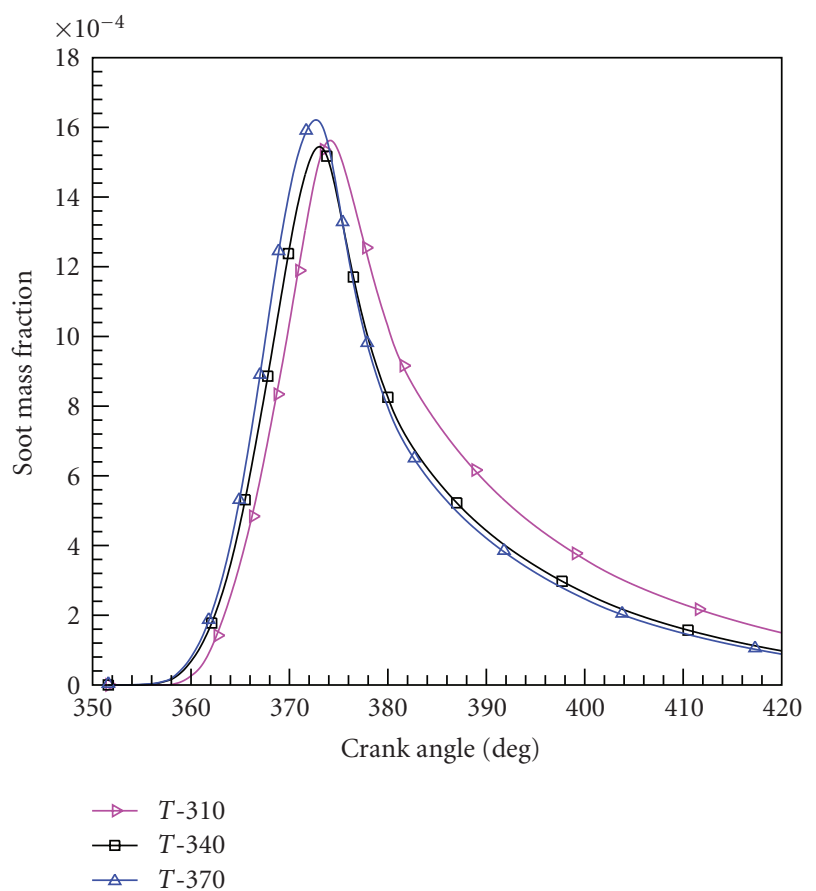

(a)



(b)

Figure 22: (a) Variations of soot mass fraction against crank angle. (b) Variations of soot mass fraction against crank angle.

Thus another sudden increase in in-cylinder temperature is observed during injection.

Figure 26 shows the produced NO in combustion chamber. The results indicate that in the case of 6 injectors the produced NO is intensely lower than the case of 1 injector. This phenomenon is justified by observing Figure 25. As

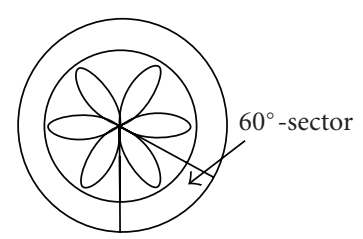

(a)

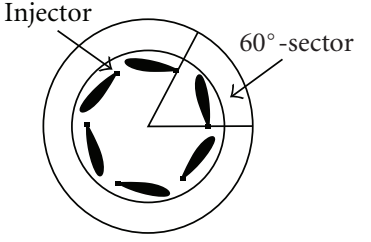

(b)
FIgURE 23: Schematically view of combustion chamber from top, (a) a combustion chamber with one injector and 6 holes, (b) a combustion chamber with six injectors each has one hole.

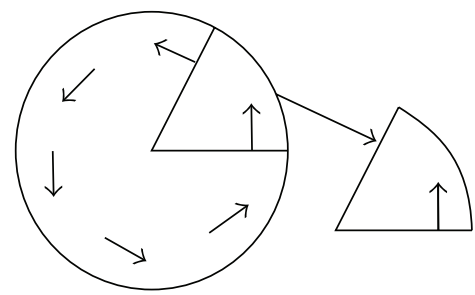

(a)

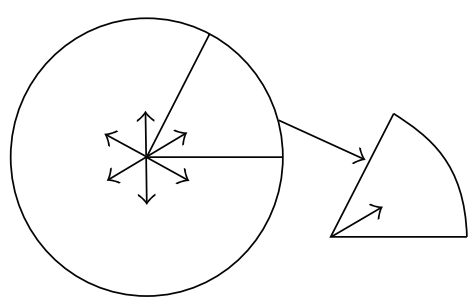

(c)

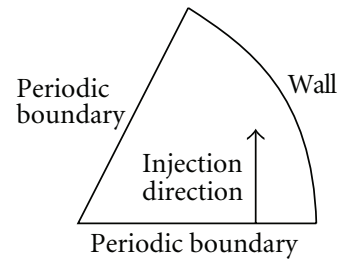

(b)

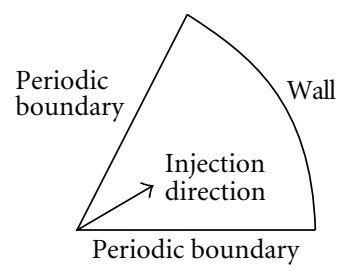

(d)
Figure 24: The combustion chamber and injection in two schematic views of $360^{\circ}$ - and $60^{\circ}$-sector.

shown in that figure the in-cylinder temperature for the case of 1 injector is higher than the case of 6 injectors, which leads to higher NO production.

Figure 27 shows the mean soot mass fraction for the cases of 1 injector and 6 injectors. As shown in that figure, soot mass fraction is disappeared for the case of 6 injectors while it is about 0.0002 for the case of 1 injector at exhaust valve crank angle. This is due to very good mixture of fuel with air in the case of 6 injectors.

\section{Conclusions}

In this study different injection strategies like different spray incoming angles, different injection cone angles, different injection timing, and different intake temperature together with the effect of multiple injector combustion chamber were investigated and discussed numerically.

The study involving in-cylinder temperature, in-cylinder pressure, $\mathrm{NO}$, and soot emissions was also reported.

First of all, the present work was compared with experimental data, and then different grids were investigated for trustworthy. This was done to ensure the reliability. By changing different parameters on a single cylinder version of 


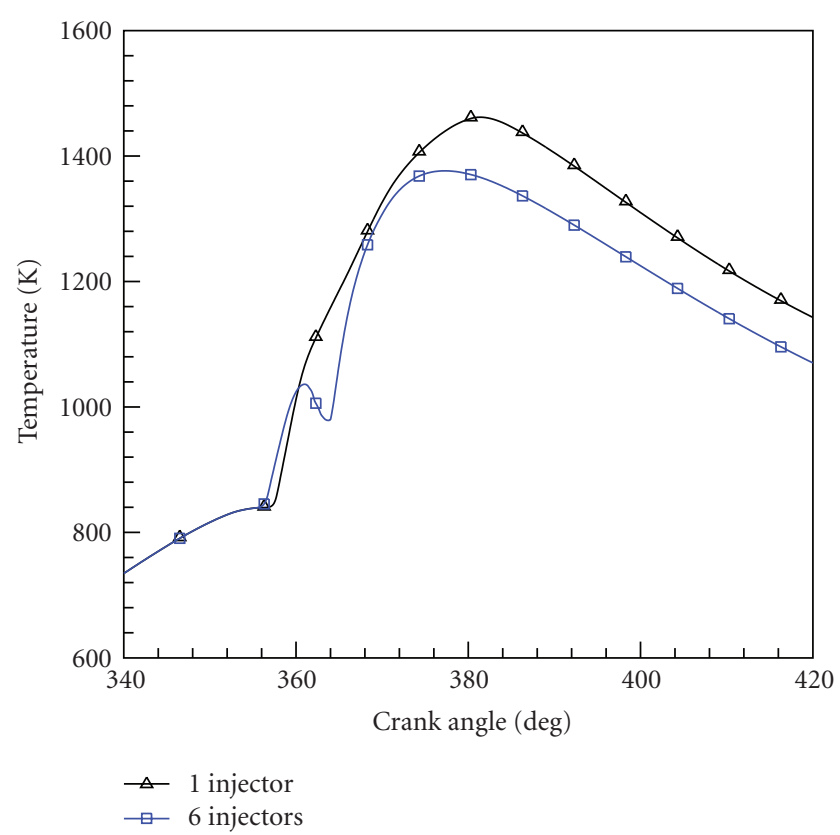

FIGURE 25: Variations of in-cylinder temperature against crank angle for two cases of one injector and six injectors.

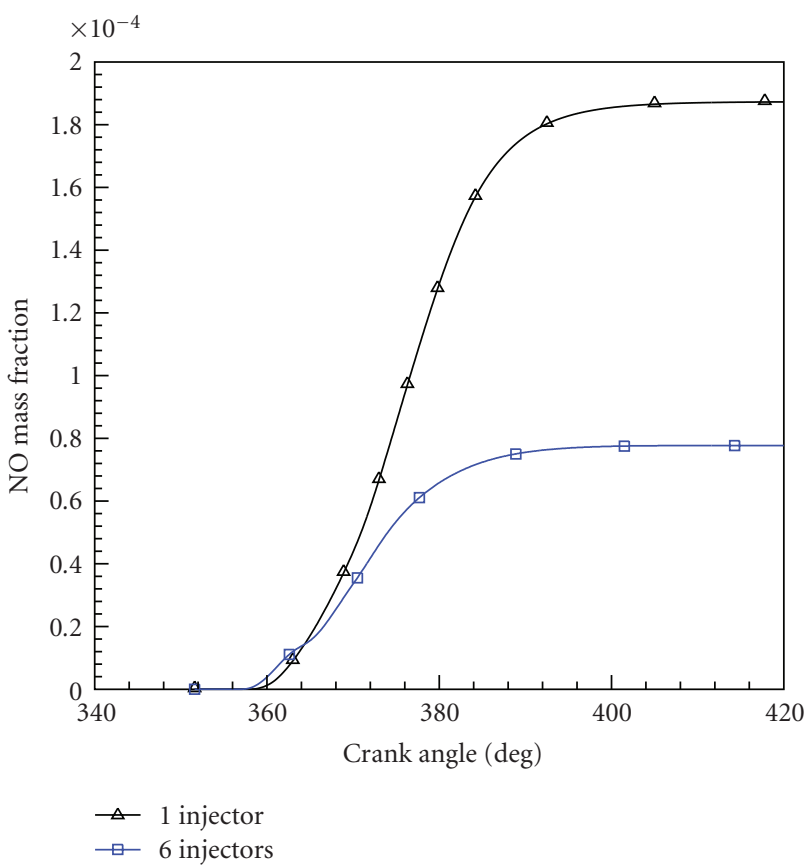

FIgURE 26: Variations of NO mass fraction against crank angle for two cases of one injector and six injectors.

the Caterpillar 3406 production truck engine, the following results were emerged.

It was shown that by increasing injection angle in the combustion chamber NO production increased severely but soot production decreased. These are due to injection directing to the piston crown which is in condition of higher temperature.

Spray cone angle was varied for produced pollutant comparison. It was shown that by increasing injection cone



FIGURE 27: Variations of soot mass fraction against crank angle for two cases of one injector and six injectors.

angle NO production increases due to better mixture but there is no difference in exiting soot although there is different rate in formation and oxidation of soot.

Furthermore it is shown that by advancing the injection timing, the in-cylinder temperature, pressure, and NO production increased, while soot production decreased. However it should be noticed that the deduction is limited to the simulated conditions. By increasing intake temperature the amount of in-cylinder temperature and NO production increased, whereas the amount of exit soot decreased.

It was showed that in the case of multiple injector combustion system (here the case of 6 injectors) the pollutants like NO and soot decreased. This was due to lower incylinder temperature and better fuel-air mixture in this case.

Finally, this paper shows the benefits of multiple injector combustion systems specially in reducing pollutant in a chosen diesel engine together with the effects of different strategies and intake conditions.

\section{References}

[1] J. M. Desantes, R. Payri, F. J. Salvador, and A. Gil, "Development and validation of a theoretical model for diesel spray penetration," Fuel, vol. 85, no. 7-8, pp. 910-917, 2006.

[2] S. W. Park, S. Kim, and C. S. Lee, "Breakup and atomization characteristics of mono-dispersed diesel droplets in a crossflow air stream," International Journal of Multiphase Flow, vol. 32, no. 7, pp. 807-822, 2006.

[3] S. S. Sazhin, "Advanced models of fuel droplet heating and evaporation," Progress in Energy and Combustion Science, vol. 32, no. 2, pp. 162-214, 2006.

[4] M. Zheng, G. T. Reader, and J. G. Hawley, "Diesel engine exhaust gas recirculation-a review on advanced and novel 
concepts," Energy Conversion and Management, vol. 45, no. 6, pp. 883-900, 2004.

[5] L. Wei, W. Ying, Z. Longbao, and S. Ling, "Study on improvement of fuel economy and reduction in emissions for stoichiometric gasoline engines," Applied Thermal Engineering, vol. 27, no. 17-18, pp. 2919-2923, 2007.

[6] T. C. Zannis, E. G. Pariotis, D. T. Hountalas, D. C. Rakopoulos, and Y. A. Levendis, "Theoretical study of DI diesel engine performance and pollutant emissions using comparable airside and fuel-side oxygen addition," Energy Conversion and Management, vol. 48, no. 11, pp. 2962-2970, 2007.

[7] L. Andreassi, S. Ubertini, and L. Allocca, "Experimental and numerical analysis of high pressure diesel spray-wall interaction," International Journal of Multiphase Flow, vol. 33, no. 7, pp. 742-765, 2007.

[8] S. Finger, D. Gelman, A. Fay, M. Szczerban, A. Smailagic, and D. P. Siewiorek, "Supporting collaborative learning in engineering design," Expert Systems with Applications, vol. 31, no. 4, pp. 734-741, 2006.

[9] D. J. Torres and M. F. Trujillo, "KIVA-4: an unstructured ALE code for compressible gas flow with sprays," Journal of Computational Physics, vol. 219, no. 2, pp. 943-975, 2006.

[10] V. Hamosfakidis and R. D. Reitz, "Optimization of a hydrocarbon fuel ignition model for two single component surrogates of diesel fuel," Combustion and Flame, vol. 132, no. 3, pp. 433450, 2003.

[11] J. K. Dukowicz, "A particle-fluid numerical model for liquid sprays," Journal of Computational Physics, vol. 35, no. 2, pp. 229-253, 1980.

[12] J. Senda and M. Kobayashi, "Modeling of diesel spray impingement on a flat wall," SAE paper 941894, SAE International, Warrendale, Pa, USA, 1984.

[13] J. K. Dukowicz, "Quasi-steady droplet phase change in the presence of convection,” Tech. Rep. LA-7997-MS, Los Alamos Scientific Laboratory, New Mexico, NM, USA, August 1979.

[14] A. B. Liu and R. D. Reitz, "Modeling the effects of drop drag and break-up on fuel sprays," SAE paper 930072, SAE International, Warrendale, Pa, USA, March 1993.

[15] Y. B. Zel'dovich, P. Y. Sadovnikov, and D. A. FrankKamenetskii, "Oxidation of nitrogen in combustion," Academy of Sciences of USSR, p. 209, 1947, translation by M. Shelef.

[16] W. Polifke, "Fundamental and practical limitations of NOx, reduction in lean-premixed combustion," in Euroconference "Premixed Turbulent Combustion: Introduction to the State of the Art”, pp. 1-17, RWTH, Aachen, Germany, 1995.

[17] B. F. Magnussen and B. H. Hjertager, "On mathematical modeling of turbulent combustion with special emphasis on soot formation and combustion," in Proceedings of the 16th International Symposium on Combustion, Pittsburgh, Pa, USA, 1977.

[18] A. D. Gosman and E. Loannides, "Aspects of computer simulation of liquid-fueled combustors," Journal of Energy, vol. 7, no. 32, pp. 482-490, 1983.

[19] N. N. Mansour, J. Kim, and P. Moin, "Near-wall K- $\varepsilon$ turbulence modeling," AIAA Journal, vol. 27, no. 8, pp. 1068-1073, 1989.

[20] C. J. Rutland, N. Ayoub, Z. Han, et al., "Diesel engine model and development and experiments," SAE paper 951200, SAE International, Warrendale, Pa, USA, 1995.

[21] G. P. Merker, C. Schwarz, G. Stiesch, and F. Otto, Simulating Combustion: Simulation of Combustion and Pollutant Formation for Engine-Development, Springer, Heidelberg, Germany, 2006.
[22] L. Dahlen, On applied CFD and model development in combustion systems development for DI diesel engines: prediction of soot mediated oil thickening, Doctoral thesis, Royal Institute of Technology, Stockholm, Sweden, 2002.

[23] J. B. Heywood, Internal Combustion Engine Fundamentals, McGraw-Hill, New York, NY, USA, 1988.

[24] R. Payri, F. J. Salvador, J. Gimeno, and J. de la Morena, "Effects of nozzle geometry on direct injection diesel engine combustion process," Applied Thermal Engineering, vol. 29, no. 10, pp. 2051-2060, 2009. 

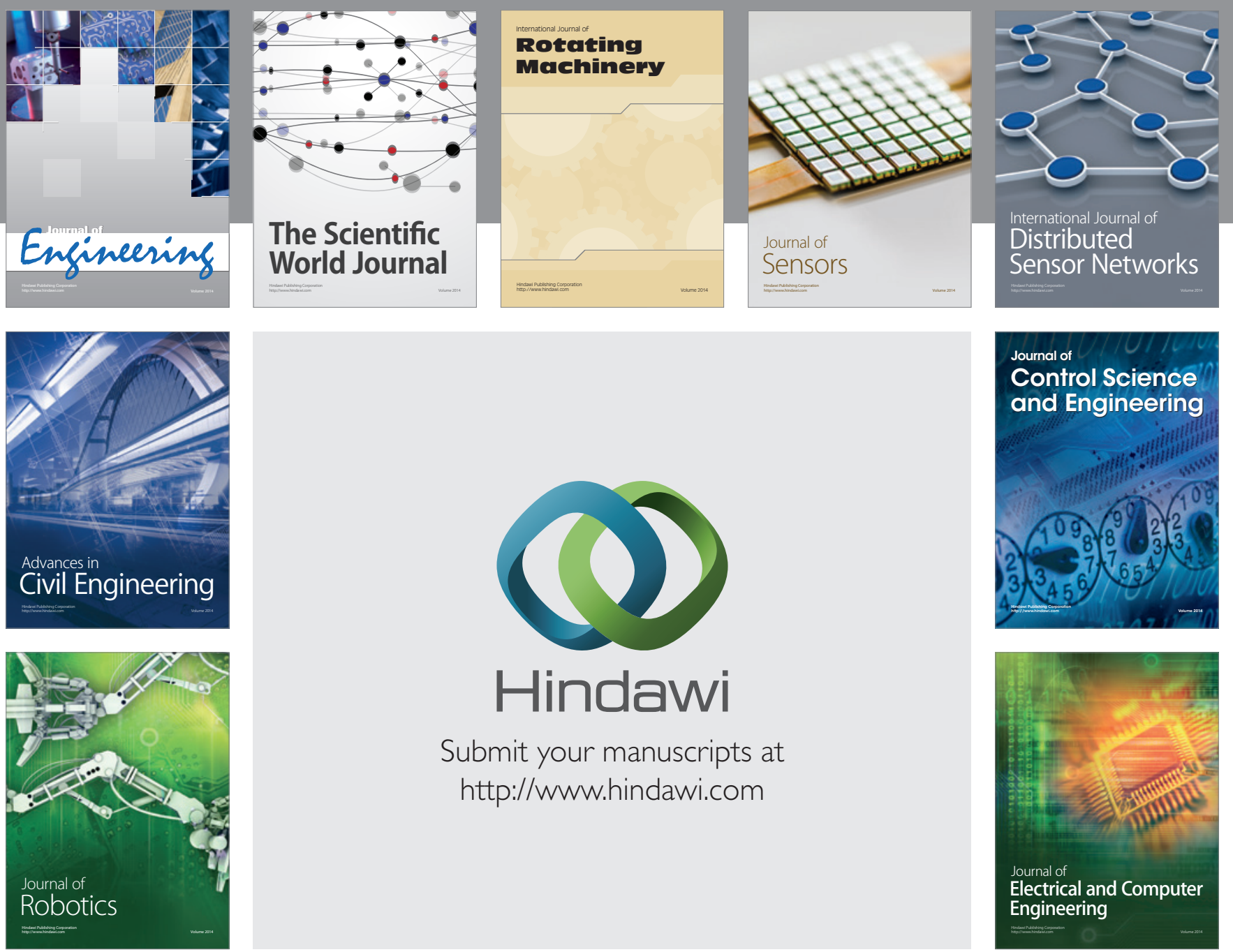

Submit your manuscripts at

http://www.hindawi.com
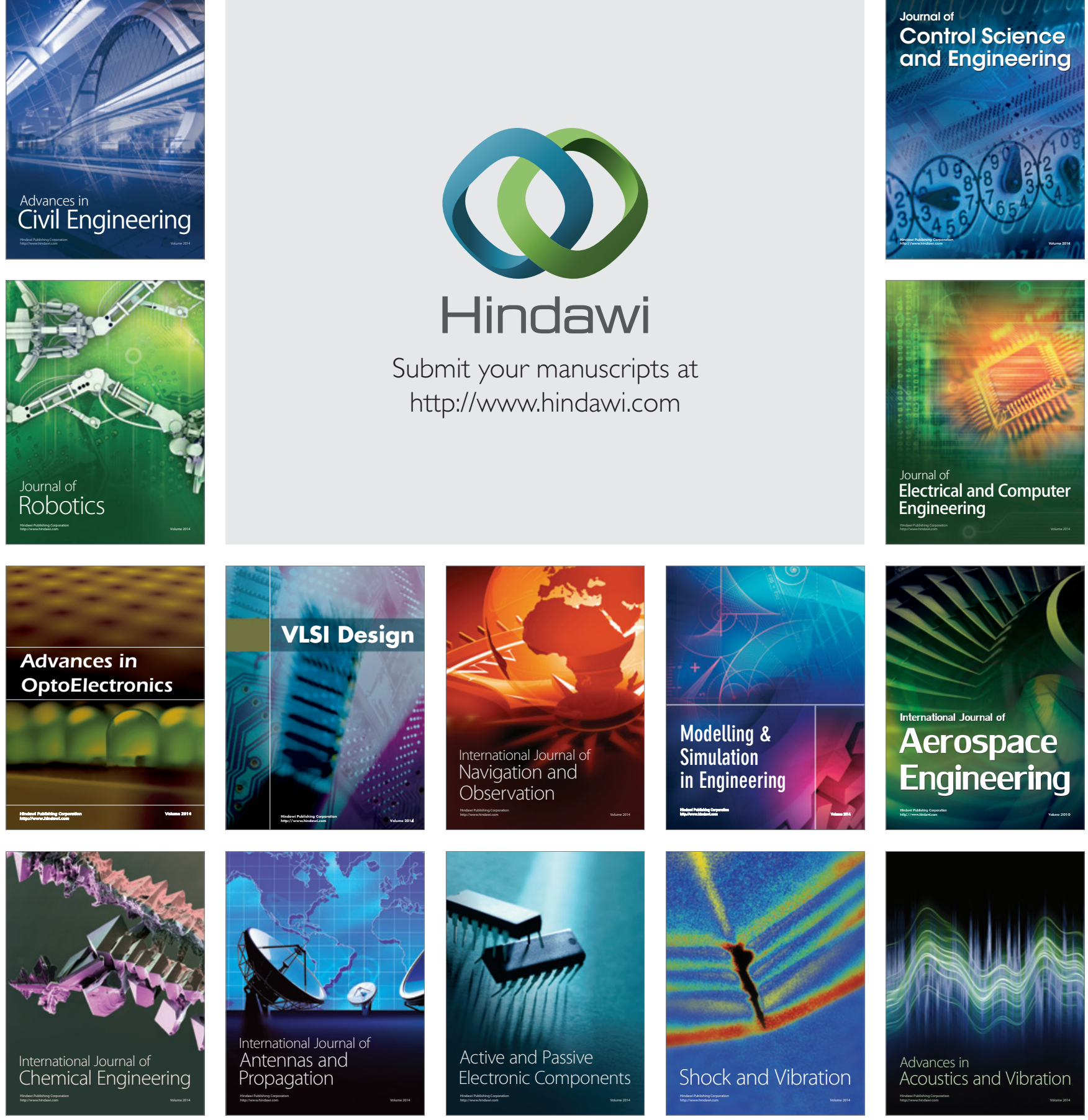